\title{
Correlation of the Archæological and Geological Records.
}

\section{By M. C. Burkitt.}

$\mathrm{F}^{0}$ $\mathrm{OR}$ the prehistorian the problem of correlating the archæological and geological records is a thankless task. No sooner has a satisfactory correlation been obtained in the study than field workers produce fresh factors which have to be accounted for and the problem is demonstrated to be still more complicated than before. However, recent researches, especially those undertaken by Mr. Reid Moir and Dr. K. S. Sandford, have thrown a flood of light on the whole matter, and while it is still too early to hope for a final solution of the knotty problem, a comparison of their work with that of earlier continental investigators does bring out certain salient points.

Although it has undergone some vicissitudes, the fourfold glacial system of Penck certainly seems to meet the facts in Nature, although the length and the intensity of the glaciations of that scheme seem to have differed in various areas, not only according to latitude (as might be expected) but also according to the longitude of the site. However, for the purpose of this article, Penck's scheme will be adopted, not least because both Mr. Reid Moir and Dr. Sandford, as well as many continental prehistorians, have a fourfold glacial system in their minds. Before tabulating the recent work in East Anglia and the Oxford district, it will be well to summarise some of the results obtained abroad: chiefly must the results of investigations at three sites, namely, Bouchiéta, Conliège, and Cotencher, be combined together.

Bouchiéta.-This site is a small cave half-way up the steep side of the Soudour hill, which rises in the middle of a tributary valley of the Ariège, close to the village of Bedeilhac and not far from Tarascon-en-Ariège. The section in the cave revealed morainic material overlaid by a deposit containing Mousterian implements. Below the level of the cave, along the hillside, can be seen the remains of another lateral moraine due to a glaciation which was not sufficiently intense to rise to the height of Bouchiéta. This glaciation must, of course, have been subsequent to the one which did reach the cave, as its moraines have not been thereby obliterated. If it had been sufficiently intense to reach the cave, doubtless the contents would have been cleaned out, and the remains left by the previous glaciation, with the deposit containing Mousterian implements resting on it, largely destroyed. The evidence at Bouchiéta thus demonstrates that some Mousterian industries are subsequent to a glaciation which was not the last.

Conliège.-In eastern France two terminal moraines can be determined, one considerably farther out in the plains than the other, due of course to the fact that the glaciation which formed it was the more intense of the two. But that the greater glaciation was not subsequent to the lesser is obvious, because if it had been, the terminal moraine of the former would have been largely

destroyed. In a deposit resting on the earlier moraine, that is, the one farthest out in the plains, and beyond the range of the subsequent and lesser glaciation, was found an Acheulean implement. It is hard to dogmatise about the exact age of a single specimen, but so far as can be judged from pictures, it does not seem to be of very early Acheulean date. The evidence at Conliège demonstrates that a part at any rate of the Acheulean culture is subsequent to the last but one important glaciation of a district.

Cotencher.- This site is in Switzerland (Neufchâtel). It is a small cave lying jüst within the orbit attained by Penck's Würm glaciation at its maximum, and it was completely filled by morainic material assignable to this last great glacial epoch. Within the morainic material were found some Mousterian tools, which must therefore have been fashioned and dropped before the Würm glaciers picked them up and deposited them at Cotencher. Cotencher demonstrates that the Mousterian culture, in part at least, was anterior to the maximum of the Würm glaciation.

But the Mousterian in France * is found with an arctic fauna and is stratigraphically later than the Acheulean, which is associated with a cool fauna. It follows, therefore, that the French Mousterian must be, in part at any rate, correlated with the Würm glaciation, it and a part at least of the Acheulean being subsequent to the Riss glacial period. Confirmation of this is given by the finds in the Somme Valley, where Acheulean industries occur in the older loess, which is found covering, and is therefore newer than, the lowest but one terrace, while it never overlies the bottom terrace-for the simple reason that at the time of its formation the bottom terrace was not there. Mousterian industries are found at the base of the younger loess, which does occur over the bottom terrace as well as over the lowest but one. Comparisons of the Somme Valley terraces with those of the Oxford district are very striking. Again, in the valley of the Garonne, Acheulean industries are found in a deposit resting on the lowest but one terrace and in the gravels of the bottom terracein the latter case in a rolled state. Once again the evidence shows that a part at any rate of the Acheulean industries can be dated to a period before the last glaciation but after the last but one.

Turning to Great Britain, the key sites in East Anglia are, in my opinion, those of Hoxne and the Cromer cliffs, to which must be added the recent discoveries in brown boulder clay at Hunstanton. Our knowledge of all three is due to the indefatigable energy of Mr. Reid Moir. Composite sections from

- I use the terms 'Mousterian in France ' and 'French Mousterian' to distinguish these industries from the many flake industries found elsewhere, for example, in Great Britain, which have often been erroneously classed as Mousterian but are better designated 'Levalloisian' or "Clactonian', and are often considerably earlier in date, being contemporary with various phases of the Acheulean culture.

$$
\text { No. 3179, VoL. 126] }
$$


these sites, together with those of the Oxford district, are given in the table below. The archæological finds from the Wolvercote channel have been correlated with the upper beds of Hoxne, the succession of industries being most helpful. The foreign evidence just detailed allows us to name the glacial periods according to the Penckian scheme. sands with the more temperate beds, probably lower Acheulean in date, of Hoxne and elsewhere. But the recent suggestions of Simpson (NATURE, Dec. 28, 1929) postulate a cold or at least cool inter-glacial at just about that time in the geological sequence of events. Assuming that the climate was temperate, as indicated by the Hanborough

TABLE OF CORRELATIONS.

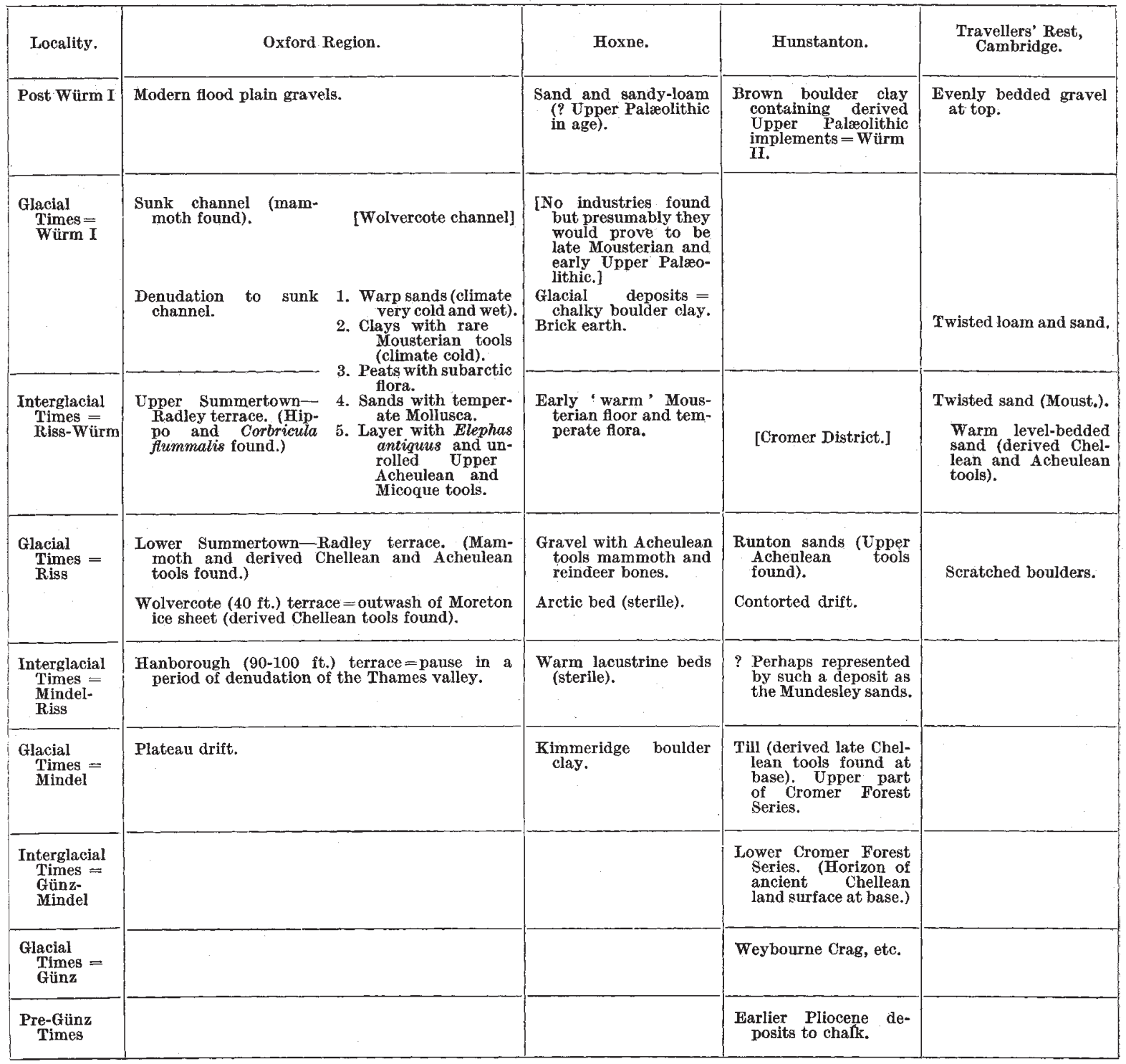

It would seem from the above that the whole period from the Eolithic industries of the sub-crag until close on chalky boulder clay times is occupied by Chellean and Acheulean industries, with which are associated at certain periods flake industries of Clactonian and Levalloisian types. The socalled 'warm' Mousterian which is earlier in date than the true Mousterian of France should, properly speaking, be included here. The only difficulty in the scheme is the correlation of the cold Mundesley terrace at Oxford and the lower bed at Hoxne, it is possible that in the intensely glaciated area around Cromer, which was more or less under the influence of the Scandinavian ice-sheets, the climate of this cool inter-glacial period was never warm enough to permit of our recognising an inter-glaciation, but that nevertheless the Cromer Till and the contorted Drift, far from being the result of one great glacial movement, are the result of two successive glaciations.

No. 3179 , VoL. 126] 